\title{
Polypropylene Composites Manufactured from Recycled Carbon Fibers from Aeronautic Materials Waste
}

\author{
Denise Hirayama ${ }^{a,{ }^{*},}$ Clodoaldo Saron ${ }^{b}$, Edson Cocchieri Botelho ${ }^{c}$, Michelle Leali Costa ${ }^{c}$, Antonio \\ Carlos Ancelotti Junior ${ }^{a}$ \\ anstituto de Engenharia Mecânica, Universidade Federal de Itajubá - UNIFEI, Itajubá, SP, Brazil \\ ${ }^{b}$ Departamento de Engenharia de Materiais, Escola de Engenharia de Lorena, Universidade de São \\ Paulo - USP, Lorena, SP, Brazil \\ ${ }^{c}$ Departamento de Materiais e Tecnologia, Faculdade de Engenharia de Guaratinguetá, Universidade \\ Estadual Paulista - UNESP, Guarantiguetá, SP, Brazil
}

Received: December 12, 2016; Revised: September 18, 2017; Accepted: September 19, 2017

\begin{abstract}
Carbon fiber composites are used in several industries such as, aerospace, automotive, civil engineering, sports goods and technical applications due to its low-weight, strength and stiffness. However, the technology of recycling of these thermosetting polymer composites remains an engineering challenge because of their cross-linked structures that impede their reprocessing by simple heating. The aim of this work was to study the influence of the amount and dimensions of carbon fibers arising from composite waste into a new composite of polypropylene matrix. In order to carry out the study, the carbon fiber composite waste has been mechanically processed for the production of chopped fibers with two different lengths $(4.5 \mathrm{~mm}$ and $3.0 \mathrm{~mm}$ ). Thermoplastic composites made of chopped carbon fiber/ polypropylene at proportions $1 \%, 5 \%$ and $7 \%$ in fiber weight content were obtained by extrusion and injection process. Then, a series of laboratory test (mechanical, thermal and morphological) were performed in order to characterize the composite material obtained. The results showed that the fibers were capable of causing a reinforcing, even though the new composite presents a complex phase system with low adhesion between the recycled carbon fibers and the polypropylene matrix.
\end{abstract}

Keywords: recycling, composite, waste, polypropylene, carbon fiber

\section{Introduction}

Carbon fiber composites have gradually replaced metals and other materials, dominating the market of aerospace, automotive, civil engineering, sports goods and technical applications mainly due to the combination of their lowweight, strength and stiffness ${ }^{1}$. However, in a few decades, these composites will become an environmental problem if there are not adequate recycling or reclaimed processes available. The destination of these waste materials will then be disposed in inappropriate locations.

There is a potential solution to this current issue, since those materials have market value and they can be returned to their life-cycle ${ }^{2}$. In other words, the recycling of waste of composite materials could become a business opportunity. To the end, some solutions for the recycling of composite materials, especially carbon / epoxy composites, might be studied from a technical and economic point of view for industrial applications ${ }^{3}$.

There are some questions that must be solved in order to have an efficient recycling process. Firstly, the composite is a mixture of different materials (fibers, polymers and fillers). Thus, to yield excellent recycled products with specific properties it is necessary to separate the different kinds of

*e-mail: denisehirayama@yahoo.com.br material or to use the mixture of the materials combined with compatibilizers. Another problem is that the thermosetting composites cannot be recycled by re-melting them, due to the presence of polymers such as, epoxy, phenolic and polyester resin which becomes infusible, insoluble and impossible to remold after the cured reactions ${ }^{4}$.

In general, there are three basic waste treatments of thermoset composites: mechanical recycling, in which waste is shredded and grinded to use in the production of the new composites; chemical recycling, in which the organic compounds can be recovered by chemical reaction (e.g. hydrolysis, glycolysis or acid digestion ${ }^{5}$ ); finally, energy recovery, in which the objective is to obtain the caloric content of the polymer ${ }^{6,7}$. Compared to other methods, mechanical recycling does not need pre-treatment of the waste, it does not use any hazardous materials, and in some case it is possible to recover both fibers and resin ${ }^{8}$.

In the mechanical recycling, the waste can be reused as fillers or as reinforcement in a new composite material. The thermosetting composite is cut into smaller pieces and then grinded to produce a particulate material. Subsequently, they are classified in different fractions by sieves: one rich in resin (powdered products) and the other rich in fibers (fibrous products). The reuse of fibrous products is more promising as reinforcement material than the reuse of powdered products, 
due to the better mechanical characteristics provided by fibrous forms. Therefore, to avoid the production of recycled composites with unknown properties, it is important to segregate the fibrous products from the powdered products ${ }^{6,9}$.

The next step for composite recycling is re-manufacturing. In general the resin (typically a thermoplastic) is mixed with fibrous products in the extruder and subsequently injected into a mold. Injection molding is the most frequently used technique because it is a versatile method of producing parts and products quickly, at low cost and with wellknown processing parameters. However, in the injection process, fiber length can be reduced. This occurs due to the increased fiber-fiber interaction and fiber-equipment wall contact that creates the friction between fibers and hence it causes alterations in fiber dimensions. In this technique, the incorporation of carbon fiber in a thermoplastic leads to a gradual increase of viscosity that means the resistance to flow is high. This resistance hinders the injection of the material into the mold. Therefore, there is maximum volume fraction of fiber, this value does not exceed $20 \%$ by volume 9 .

In order to produce a strong interface which can transfer the load efficiently from the matrix to the fiber, the carbon fiber could receive a specific treatment to each matrix before being utilized in the manufacture of composites. This treatment is called sizing ${ }^{10}$. In the case of recycling carbon fibers from composite waste, this enhancement in the interfacial adhesion can complicate the incorporation of fiber into the thermoplastic matrix, especially when the composite that will be recycled is formed by epoxy resin. In a mixture of a fiber (hydrophilic coating) with a thermoplastic (hydrophobic characteristic) created an interface of low adhesion, that can result in a reduction of mechanical properties ${ }^{6,11}$.

The crystallinity of resin, viscosity of composites, the coating of the fibrous content, and the fiber length are the main characteristics that could influence mechanical properties of composite material ${ }^{8,12}$.

The aim of this work was to study the influence of the amount and dimensions of recycled carbon fibers on properties of the polypropylene composite. In order to realize this study, the carbon fiber composite waste was subjected to mechanical recycling for the production of particles with two different lengths; these particles were used for the preparation of thermoplastic composites with polypropylene at 1\%, 5\% and $7 \% \mathrm{w} / \mathrm{w}$ of the fiber. Then, mechanical, thermal and morphological analyses were performed to characterize the composite material.

\section{Experimental Procedures}

\subsection{Materials}

\subsubsection{Carbon fiber composite waste (CFCW)}

The recycled carbon fibers used as reinforcement to produce the composites were from a laminate $(300 \mathrm{~mm} \mathrm{x}$ $300 \mathrm{~mm} \times 3 \mathrm{~mm}$ ) fabricated at São Paulo State University
(UNESP). The laminate was based on epoxy matrices (F155) and carbon fiber fabric reinforcements (Plain Weave).

\subsubsection{Polymeric matrix}

The polymer employed in production of composites of recycled carbon fiber/polypropylene was the injection grade polypropylene (PP) pellets, which were supplied by Braskem. Polypropylene was selected as the polymeric matrix due to its wide commercial use and low cost.

\subsection{Methods}

\subsubsection{Recycled carbon fiber (RCF) preparation}

The CFCW laminate was initially cut into a dimension of approximately $30 \mathrm{~mm} \times 150 \mathrm{~mm}$, and subsequently grinded in a knife mill (MOMESSO) to generate particles of lengths between 0.65 to $12 \mathrm{~mm}$ and diameters between 0.08 to 1.37 $\mathrm{mm}$. In this preparation, no process to remove resin from carbon fiber was performed, therefore the carbon fibers were contaminated by epoxy resin. However, for convenience, this material will be referred to as recycled carbon fiber (RCF), from here onwards.

\subsubsection{RCF characterization}

In order to determine the presence of epoxy resin over the recycled carbon fiber, chemical analyses of RCF was carried out. They were conducted using a spectrometer Shimadzu IR Prestige-21 with a resolution of $4 \mathrm{~cm}^{-1}$ with 64 scans. Fourier transform Infrared (FTIR) analyses were performed in transmittance mode soon after dilution in $\mathrm{KBr}$ pellets, according to ASTM 1252 standard.

Thermogravimetric analyses (TGA) were carried out in a simultaneous thermal analyzer (NETZSCH model STA 449 F3 Jupiter) at a heating rate of $10^{\circ} \mathrm{C} \mathrm{min}^{-1}$ and a nitrogen flow of $100 \mathrm{~mL} \mathrm{~min}^{-1}$ to determine the organic content present in the recycled carbon fiber. The mass of the sample used in each analysis was approximately $10 \mathrm{mg}$.

The morphology of the RCF surface was investigated using a scanning electron microscope (SEM), the LEO 1450 VP. Secondary electron images were obtained by using an accelerating voltage of $20 \mathrm{kV}$ and 500x magnification. The intention here was to verify if recycled carbon fibers are coated by resin or not.

The grinded RCF were sorted by Tyler sieves. The portion of the fiber retained between the 20 mesh sieve (openings of $0.841 \mathrm{~mm}$ ) and the 30 mesh sieve (openings of 0.595 $\mathrm{mm}$ ) has been referred to as type L, while the fibers which went through the 30 mesh sieve were designated as type $\mathrm{S}$. The length of 400 fibers of each type were measured using a light microscope FWL-SMZ 7.5 by Feldman Wild Leitz at $10 \mathrm{x}$ and 50x magnification.

\subsubsection{Manufacture of the PP/RCF composites}

$\mathrm{PP} / \mathrm{RCF}$ composites were produced by extrusion in an Imacon with a temperature profile of $170 / 180 / 190 / 200{ }^{\circ} \mathrm{C}$ 
from the alimentation zone to the matrix. The resulting materials of this process were dried at $75^{\circ} \mathrm{C}$ by $4 \mathrm{~h}$ to remove the remaining moisture. The specimens for tensile testing were prepared by injection molding in a Spazio DW-130, with $1 \%, 5 \%$ and $7 \% \mathrm{w} / \mathrm{w}$ of fibers, respectively. All characterizations of composites were done with these tensile testing specimens.

\subsubsection{Characterization of $\mathrm{PP} / \mathrm{RCF}$ composites}

In order to determine the maximum content of carbon fiber that can be added into the composite during the injection process, the melting flow index (MFI) was measured. For this purpose, specimens were grinded in a knife mill to generate a particle size of around $5 \mathrm{~mm}$ in length. This material was then analyzed in an extruder plastometer (Ceast 7021) at $230^{\circ} \mathrm{C}$ and with the application of $2.16 \mathrm{~kg}$ weight, according to ASTM D1238.

Differential scanning calorimetry (DSC) was used to determinate the crystallinity of the matrix present in the composite. The analyses were performed in a DSC Q20 (TA Instrument) at a heating rate of $10^{\circ} \mathrm{C} / \mathrm{min}$ using two heating cycles from $-30^{\circ} \mathrm{C}$ to $280^{\circ} \mathrm{C}$ in a nitrogen atmosphere of $50.0 \mathrm{~mL} / \mathrm{min}$.

The degree of crystallinity $(\mathrm{Xc})$ was calculated by the ratio between the enthalpy of fusion measured at the melting point $\left(\Delta \mathrm{H}_{\mathrm{m}}\right)$, and the enthalpy of fusion of $100 \%$ crystalline PP $\left(\Delta \mathrm{H}_{\mathrm{m}}^{\mathrm{o}}\right)$ expressed in percentage. For polypropylene, the assumed $\Delta \mathrm{H}^{\mathrm{o}}{ }_{\mathrm{m}}$ value was $209 \mathrm{~J} / \mathrm{g}^{13}$, however this value must be proportional to the polymeric mass present in the composite. Thus to determine the degree of crystallinity of the composite, Equation 1 was used:

$$
X_{C}=\frac{\Delta H_{m}}{\Delta H^{o}{ }_{m}(1-x)} \cdot 100
$$

where $x$ represents the fiber weight fraction ${ }^{14}$.

Tensile strength tests were performed according to ASTM D 256 standards to evaluate the mechanical properties of composite with type L fiber and type $S$ fiber. The six specimens were carried out in a universal testing machine (EMIC DL 3000 ) with a load cell of $5 \mathrm{kN}$ at a speed of $10 \mathrm{~mm} \mathrm{~min}^{-1}$.

The interfacial adhesion between recycled carbon fiber and polypropylene was evaluated by the fracture surface of the PP/RCF composite. The analyses were performed in a scanning electron microscope (SEM) LEO $1450 \mathrm{VP}$ instrument. Secondary electron images were obtained by using an accelerating voltage of $20 \mathrm{kV}$ and $10,000 \mathrm{x}$ magnification.

\section{Results and Discussion}

\subsection{Recycled carbon fiber (RCF)}

For the understanding of the mechanical behavior of PP/RCF composite firstly, the chemical and morphological properties of recycled carbon fiber were studied. Fig. 1 shows the infrared spectra of recycled carbon fiber. It is possible to identify absorption bands, such as, $3650-3000 \mathrm{~cm}^{-1}$, that are assigned to the axial deformation of O-H; $2940 \mathrm{~cm}^{-1}$ and $2880 \mathrm{~cm}^{-1}$, which is due to the axial deformation of $\mathrm{C}-\mathrm{H}$ present in the epoxy structure ${ }^{15} ; 1655 \mathrm{~cm}^{-1}$, that is attributed to stretching vibration of $\mathrm{C}=\mathrm{C} ; 1272 \mathrm{~cm}^{-1}$, related to the stretching vibration $\mathrm{C}-\mathrm{O}-\mathrm{C}$ and at $1050 \mathrm{~cm}^{-1}$, that is referred to the aliphatic-aromatic ether linkage. All these bands are typical epoxy resin bands ${ }^{16}$ indicating that epoxy resin remained in the recycled carbon fibers.

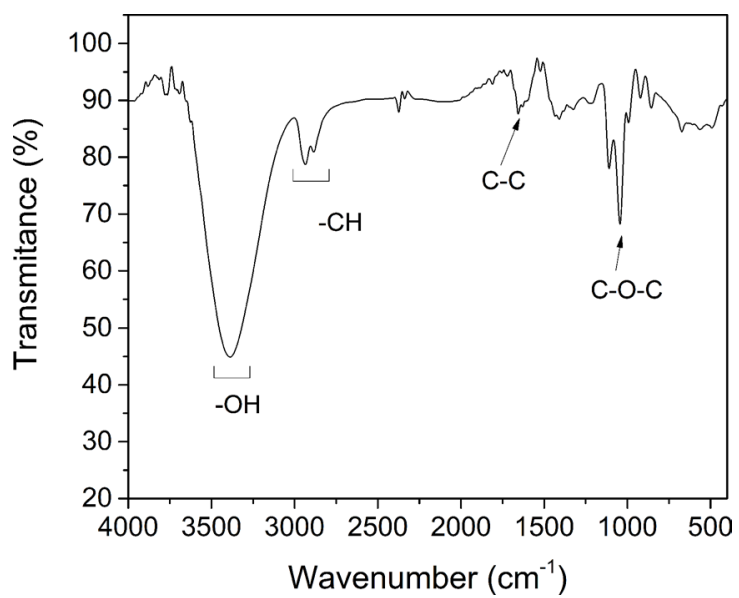

Figure 1. FTIR spectrum recycled carbon fiber.

The TGA and derivative thermogravimetric analysis (DTG) of recycled carbon fiber (Fig. 2) were obtained in order to confirm and quantify the presence of epoxy resin in this material. The degradation of the sample began at about $330^{\circ} \mathrm{C}$ and it was completely degraded at about $500^{\circ} \mathrm{C}$. The loss of weight was approximately $20 \%$ in this range of temperature. From DTG curves, it observed that there is a unique event with peak temperature at $380^{\circ} \mathrm{C}$. Comparing these values with the literature ${ }^{17}$, it can be confirmed that it refers to the decomposition of epoxy. With these results one could estimate that in the recycled carbon fiber composite there is $20 \% \mathrm{w} / \mathrm{w}$ of epoxy resin.

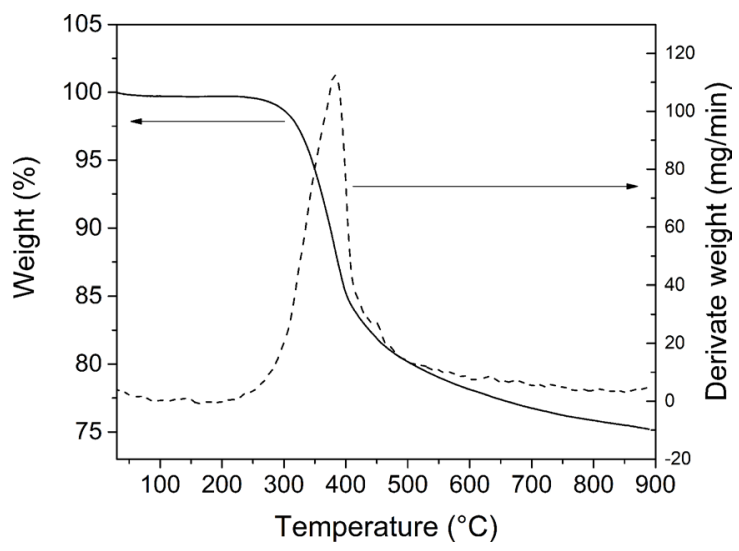

Figure 2. TGA and DTG curves of recycled carbon fiber. 
Fig. 3 shows the SEM photomicrograph of the recycled carbon fiber. In the RCF there are two distinct regions: The first one (right image), where the fibers are together and aligned; and the second one (left image), where they were separated and consequently not orientated. Furthermore, white particles with non-uniformed size/format spread over the fibers were observed. These particles might be the resin of composite waste that fragmented after the grinding process. Therefore, this recycling process resulted in a carbon fiber that contains fiber coated by resin, uncoated fiber, and the resin particles.

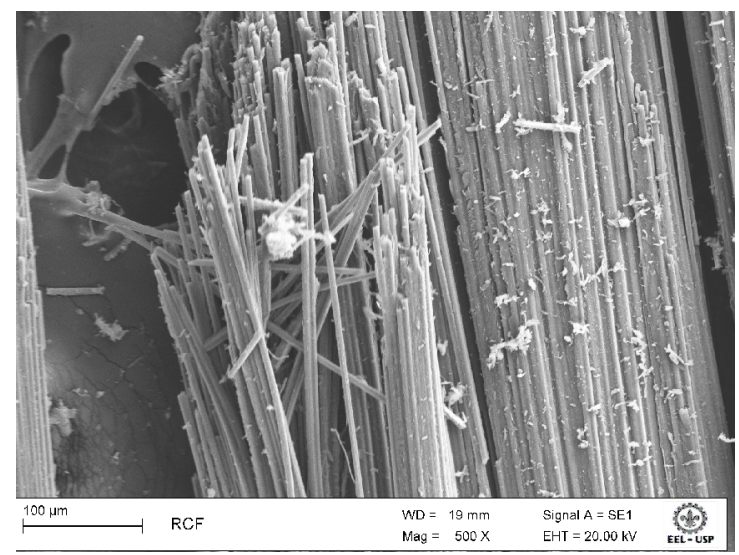

Figure 3. SEM photomicrograph of recycled carbon fiber.

Given this difference of format present in recycled carbon fiber, the incorporation of RCF in thermoplastic matrix (polypropylene) led to the formation of complex systems with interfacial regions between carbon fiber /PP, epoxy resin/PP, and carbon fiber/epoxy/PP which can affect the mechanical properties of the material.

(a)

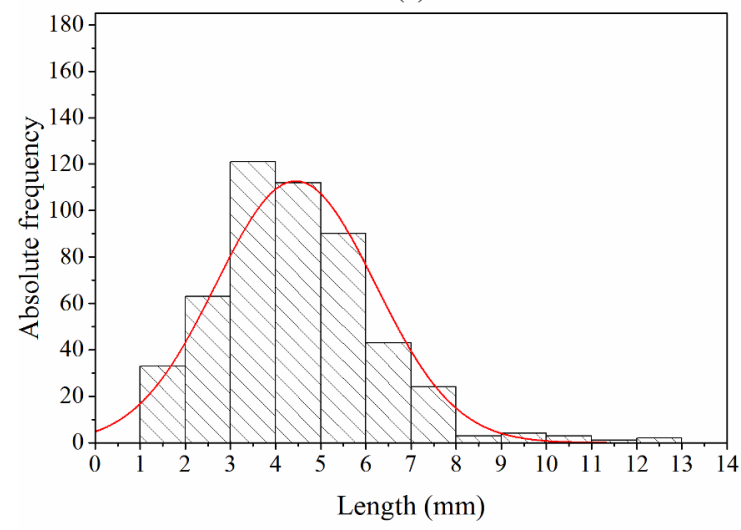

\begin{tabular}{c|ccc}
\hline $\begin{array}{c}\text { AVERAGE } \\
(\mathrm{mm})\end{array}$ & $\begin{array}{c}M \hat{A X} \\
(\mathrm{~mm})\end{array}$ & $\begin{array}{c}\text { MIN } \\
(\mathrm{mm})\end{array}$ & $\begin{array}{c}\text { DEVIATION } \\
(\mathrm{mm})\end{array}$ \\
\hline 4.45 & 12.63 & 1.16 & 1.77 \\
\hline
\end{tabular}

Figure 4. Histogram of length: type L fiber (a) and type S fiber (b).
The grinded recycled carbon fibers were sorted in type $S$ fiber and type L fiber by Tyler sieves. Fig. 4 shows the fiber length histograms in which unimodal shapes are exhibited with data in the range of $0 \mathrm{~mm}$ to $14 \mathrm{~mm}$. According to the histogram, the length of the type S fibers (Fig. 4.a) are in the interval of $2-3 \mathrm{~mm}$ and the length of the type $\mathrm{L}$ fibers (Fig. 4.b) are 3-4 $\mathrm{mm}$. This indicates that there is real difference in the length for each type of fiber using this separation method.

According to the average values of fiber lengths shown in Fig. 4, the type L fibers $((4.45 \pm 1.77) \mathrm{mm})$ were $50 \%$ larger than the type $S$ fibers $((2.97 \pm 1.47) \mathrm{mm})$. These results in addition to the histograms above, suggest that the separation of fiber was efficient and the two groups of fibers are significantly different.

\subsection{PP/RCF composite}

The effects of the addition of recycled carbon fiber in polypropylene were evaluated by chemical, mechanical and morphological analyses of the composite. MFI values (Fig. 5), including standard derivation results, were used to determine the maximum carbon fiber content in the composite. The addition of carbon fiber tends to reduce the melt flow index, with a considerable reduction only for the composite concentration of the $7 \% \mathrm{w} / \mathrm{w}$ carbon fiber. This effect was observed for both fiber lengths (type L and type S).

Because the melt flow index is inversely proportional to viscosity, the results indicated that the addition of carbon fiber leads to an increase in viscosity for the composite. With this increase, the internal friction between polymer chains is increased, resulting in an increase in the temperature of material during the injection molding. This could cause unviability of processing or degradation of material.

(b)

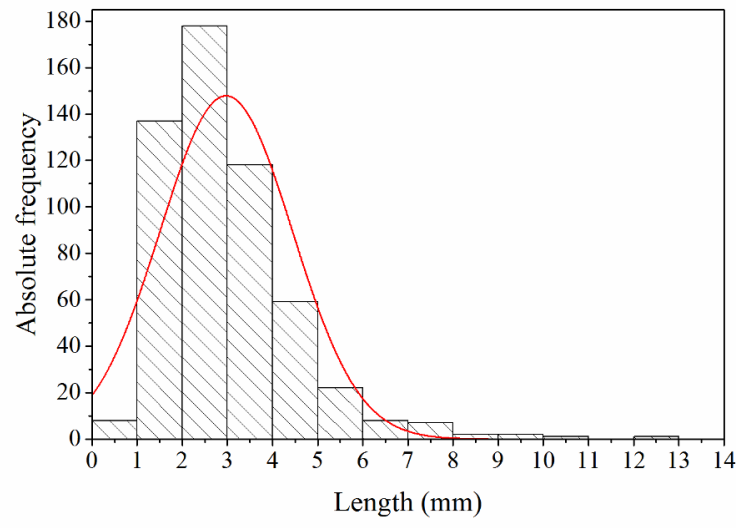

\begin{tabular}{c|ccc}
\hline $\begin{array}{c}\text { AVERAGE } \\
(\mathrm{mm})\end{array}$ & $\begin{array}{c}M A X \\
(\mathrm{~mm})\end{array}$ & $\begin{array}{c}\text { MIN } \\
(\mathrm{mm})\end{array}$ & $\begin{array}{c}\text { DEVIATION } \\
(\mathrm{mm})\end{array}$ \\
\hline 2.97 & 12.46 & 0.65 & 1.47 \\
\hline
\end{tabular}




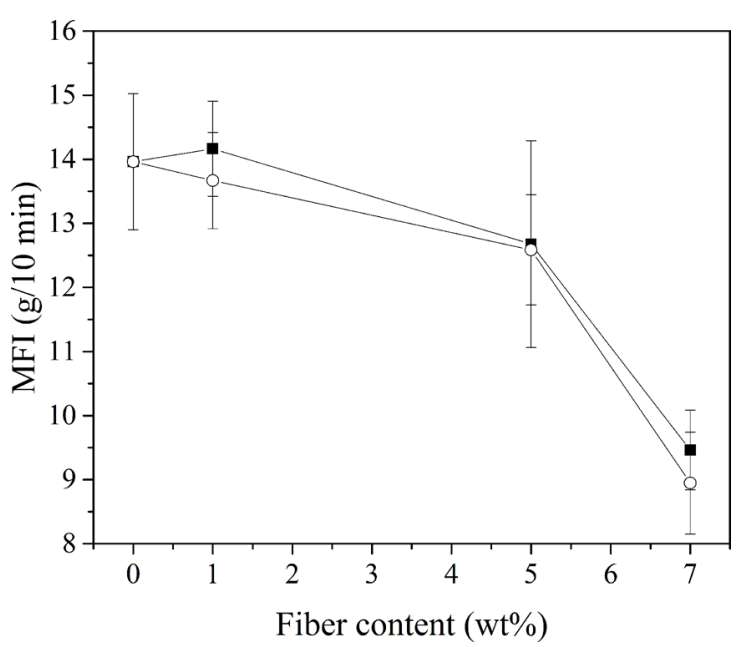

Figure 5. MFI of PP/RCF composite: type L fiber (empty circle) and type $\mathrm{S}$ fiber (filled square).

In an attempt to increase the carbon fiber in the composite, another composite of $10 \% \mathrm{w} / \mathrm{w}$ of RCF was manufactured; however, this did not succeed because the viscosity of the composite increased in a manner that, even with changes in processing parameters, specimens still were not produced. It was concluded that, in this processing, the limit in amount of carbon fiber was $7 \% \mathrm{w} / \mathrm{w}$.

The degree of crystallinity of the matrix present in the composite was studied by DSC analysis. The parameters obtained in these analyses (Tab. 1) were melting temperature $(\mathrm{Tm})$, crystallization temperature (Tc), melting enthalpy $(\Delta \mathrm{Hm})$, crystallization enthalpy $(\Delta \mathrm{Hc})$ and degree of crystallinity $(\mathrm{Xc})$.

The melting temperature (Tm) of the polymer was slightly influenced by adding carbon fiber, however the crystallization temperature (Tc) increased significantly with the incorporation of the fiber. The crystallization temperatures varied from $113^{\circ} \mathrm{C}$ to $119^{\circ} \mathrm{C}$. The difference was $6^{\circ} \mathrm{C}$ when compared to the composite of $7 \% \mathrm{w} / \mathrm{w}$ of carbon type $\mathrm{L}$ fiber with pure polypropylene.

The addition of carbon fiber into polypropylene also results in changes in the degree of crystallinity $(\mathrm{Xc})$ of a composite. In the composite of type L fiber, the incorporation of small amounts of fiber $(1 \% \mathrm{w} / \mathrm{w})$ decreased the Xc $6 \%$, and in the case of larger amounts of fiber $(7 \% \mathrm{w} / \mathrm{w})$ the loss was $14 \%$. Meanwhile in the composite with $5 \% \mathrm{w} / \mathrm{w}$ of fiber the crystallinity was larger than pure polypropylene, showing an increase of $8 \%$.

For composite with type $\mathrm{S}$ fiber, the degree of crystallinity increased to $39 \%$ with small amounts of fiber, but with the increase of carbon fiber to $7 \% \mathrm{w} / \mathrm{w}$ the Xc values tended to lower, as occurred in the composite with type $\mathrm{L}$ fiber. These results suggest that, depending on the type of fiber, the insertion of carbon fiber in the polymeric mass may or may not stimulate the nucleation of crystallites.

These changes in thermal properties of polymeric matrix can be explained by the nucleation ability of the carbon fiber during the crystallization of polypropylene ${ }^{18}$. Higher thermal conductivity of the carbon fiber as compared to that of the polymer may be responsible for the change in crystallinity temperature and the degree of crystallinity. The heat produced by carbon fiber could change the heating rate and consequently the crystallization mechanism.

Tab. 2 summarizes the mean and standard derivation of the tensile strength, Young's modulus and elongation at break of the PP/RCF composite with $1 \%, 5 \%$ e $7 \% \mathrm{w} / \mathrm{w}$ of fiber content. The mechanical properties of all composites are gradually changed with the increase of carbon fiber content. The tensile strength tends to increase with the addition of carbon fiber content. This behavior was also observed in Young's modulus of composites with the incorporation of carbon fiber. Finally, the elongation at break decreases with the addition of type $\mathrm{S}$ and $\mathrm{L}$ fibers as expected for the reinforced composite.

In general, the use of type L fibers in composites showed better mechanical properties than type $S$ fibers. Bearing in mind the type $\mathrm{S}$ fibers are smaller than type L, mechanical properties such as tensile strength and Young's modulus increase with increasing fiber length due to the larger anchorage area in longer fibers. In this case, more force is necessary to break the fiber and matrix interaction.

In the analyses of the composite with the best properties ( $7 \% \mathrm{w} / \mathrm{w}$ of type $\mathrm{L}$ fiber), it was observed that the tensile strength increased 16\% and Young's modulus increased 54\% in relation of PP. Considering the difference of the properties between carbon fibers $(\sigma=4900 \mathrm{MPa} \text { and } \mathrm{E}=230 \mathrm{GPa})^{19}$ and

Table 1. Thermal properties of PP/RCF composite.

\begin{tabular}{cccccccc}
\hline Samples & $\begin{array}{c}\text { Amount of } \\
\text { fiber }(\% \mathrm{w} / \mathrm{w})\end{array}$ & Type of fiber & $\mathrm{Tc}\left({ }^{\circ} \mathrm{C}\right)$ & $\Delta \mathrm{Hc}(\mathrm{J} / \mathrm{g})$ & $\mathrm{Tm}\left({ }^{\circ} \mathrm{C}\right)$ & $\Delta \mathrm{Hm}(\mathrm{J} / \mathrm{g})$ & $\mathrm{Xc}(\%)$ \\
\hline PP & 0 & - & 113 & 83.1 & 161 & 74.0 & 36 \\
PP1CFL & 1 & $\mathrm{~L}$ & 116 & 81.9 & 161 & 70.2 & 34 \\
PP5CFL & 5 & $\mathrm{~L}$ & 119 & 86.2 & 162 & 76.4 & 39 \\
PP7CFL & 7 & $\mathrm{~L}$ & 119 & 69.6 & 161 & 59.5 & 31 \\
PP1CFC & 1 & $\mathrm{~S}$ & 116 & 93.4 & 160 & 80.5 & 39 \\
PP5CFC & 5 & $\mathrm{~S}$ & 117 & 91.0 & 161 & 79.0 & 40 \\
PP7CFC & 7 & $\mathrm{~S}$ & 118 & 85.5 & 161 & 73.1 & 38 \\
\hline
\end{tabular}


Table 2. Mechanical properties of PP/RCF composite.

\begin{tabular}{cccc}
\hline Samples & Tensile strength $(\mathrm{MPa})$ & Young's modulus $(\mathrm{GPa})$ & Elongation at break $(\%)$ \\
\hline PP & $26.6 \pm 0.2$ & $1.4 \pm 0.3$ & No break \\
PP1CFC & $28.3 \pm 0.4$ & $1.4 \pm 0.1$ & $16.0 \pm 0.4$ \\
PP5CFC & $29.5 \pm 0.6$ & $1.8 \pm 0.3$ & $12.0 \pm 1.6$ \\
PP7CFC & $28.9 \pm 0.9$ & $2.4 \pm 0.3$ & $8.5 \pm 1.8$ \\
PP1CFL & $28.2 \pm 0.2$ & $1.5 \pm 0.1$ & $16.3 \pm 1.7$ \\
PP5CFL & $30.7 \pm 0.2$ & $1.8 \pm 0.1$ & $10.2 \pm 1.1$ \\
PP7CFL & $30.9 \pm 0.3$ & $2.1 \pm 0.4$ & $8.6 \pm 1.4$ \\
\hline
\end{tabular}

$\operatorname{PP}(\sigma=18 \mathrm{MPa} \text { and } \mathrm{E}=1.5 \mathrm{GPa})^{19}$, it was expected that these properties be higher, that the increase be $2000 \%$ in tensile strength and $1000 \%$ in Young's modulus for composite with $7 \% \mathrm{w} / \mathrm{w}$ of carbon fiber, according to mixture rule.

In order to explain low gain on mechanical properties with the addition of fibers in the composite, the distribution length should first be analyzed. As observed, the recycled carbon fibers exhibit a large range of lengths. These differences cause negative impacts on the composite properties because some fibers can act as stress concentrators. From morphological analyses of RCF, it was conclude that the recycled carbon fibers are contaminated by epoxy resin. Low affinity of these contaminated with PP is the second reason that composite does not reach the maximum values of mechanical properties. The degree of crystallinity of matrix could also be the cause of this behavior, however the increase of carbon fiber in composites lead to the opposite trend between mechanical properties to degree of crystallinity. Thus degree of crystallinity of the matrix was not significant in mechanical properties.

The SEM micrographs of composite with $1 \%, 5 \%$ and 7 $\% \mathrm{w} / \mathrm{w}$ of the carbon fiber content are presented in Fig. 6 . The fracture surface images of the composite show agglomerated fibers in the polymeric matrix; this was expected since the carbon fiber used to produce the composite were contaminated by resin. However, this characteristic of reinforcing can decrease the adhesion between the new matrix and the fibers, consequently reducing mechanical properties.

To evaluate the interfacial adhesion of fibers, the analyses focused on the region between recycled fiber and PP matrix. In all composite, spaces between matrix and fiber can be visualized (black area around the fiber), meaning that the fractured mechanism occurred in the interfacial region.

Note that the failure took place within the matrix and that the fibers remained intact, indicating that they are not the source of crazing. The formation of complex system composed by polypropylene, carbon fiber, and epoxy can be the reason for this behavior. The epoxy resin (hydrophilic) is not compatible with polypropylene (hydrophobic), which results in low adhesion between fiber and matrix. The addition of a compatibilizer can be an alternative to improve the interaction between a coated fiber and PP, however this would only work on fibers impregnated with resin. (a)

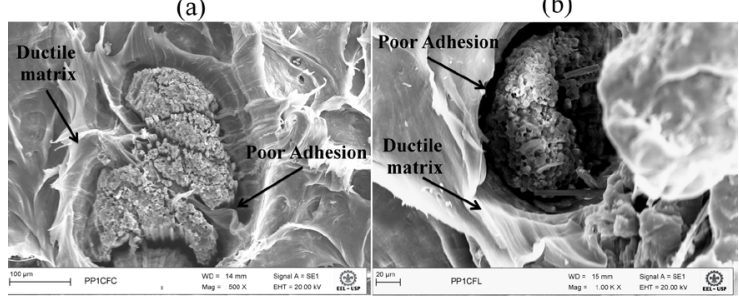

(c)

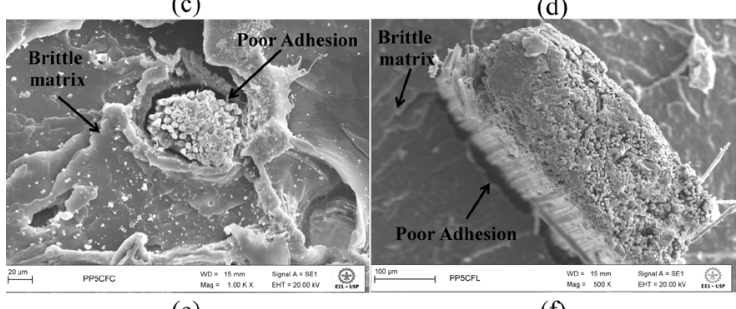

(e)

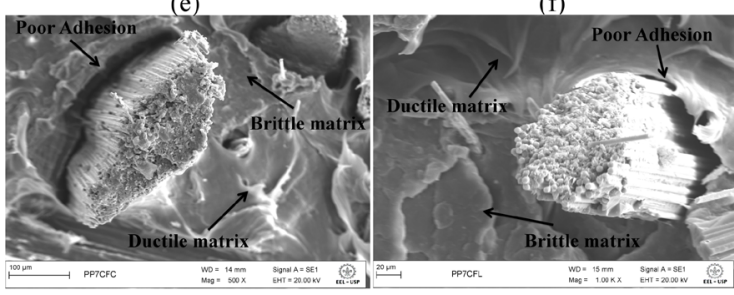

Figure 6. SEM photomicrograph of PP/RCF composite: PP1CFC (a), PP1CFL (b), PP5CFC (c), PP5CFL (d), PP7CFC (e) and PP7CFL (f).

In type $\mathrm{L}$ and $\mathrm{S}$ fibers of same fiber ration the same morphological behavior was observed. The matrix around the fibers shows a rough textured, whitish substance for composites with $1 \% \mathrm{w} / \mathrm{w}$ of carbon fiber, leading to a ductile material behavior. In the composite with $5 \% \mathrm{w} / \mathrm{w}$ of carbon fiber the matrix was smooth, which indicated that the breaking of the matrix was brittle. The ductile and brittle behaviors also occurred in the composite with $7 \% \mathrm{w} / \mathrm{w}$ of carbon fiber. It can be concluded that the increase of carbon fibers modifies the failure mode from ductile to fragile, which was corroborated in mechanical results.

The SEM images show that the fibers were oriented in the perpendicular direction of fracture surface, hence in the same direction of the applied tension in the tensile testing. This is consequence of the injection flux that aligned the fibers and distributed one in uniform form. For this reason, comparing the mechanical properties of composite with 
the polymeric matrix, the addition of recycled carbon fiber led to a positive effect. The tensile strength and Young's modulus increased and the elongation at break decreased with addition of fiber.

\section{Conclusions}

Analysis of recycled carbon fibers showed that they are composed of a mixture of the fiber coated with epoxy resin, the uncoated fiber, and the epoxy resin particles. The epoxy contamination represents $20 \% \mathrm{w} / \mathrm{w}$ of the material. Therefore, the addition of the recycled carbon fiber into a thermoplastic matrix (polypropylene) must take into account the interaction of carbon fiber /PP, epoxy resin/PP, carbon fiber/epoxyresin.

The PP/RCF composite produced with two different lengths $(4.5 \mathrm{~mm}$ and $3.0 \mathrm{~mm})$ allowed a maximum addition of $7 \% \mathrm{w} / \mathrm{w}$ of recycled carbon fiber. The large range of fiber length distribution, the contamination by epoxy resin and poor adhesion between fiber and matrix are the reasons why the mechanical properties did not improve. The degree of crystallinity of the matrix was not significant in the mechanical properties.

Even though the new composite presents a complex phase system, the mechanical results showed that the fibers were capable of causing a reinforcement, which was more significant in the type L fiber. This occurred due to fiber length, fiber orientation in relation to applied tension and the uniform distribution of particles in the specimens.

Therefore, this complex system must be studied to improve the interaction between the coated fiber and the thermoplastics; this could, consequently, establish good applications for these recycled materials, as in the automobile industry.

\section{Acknowledgments}

The authors would like to thank CAPES and FAPEMG for finance support.

\section{References}

1. Chung DDL. Composites get smart. Materials Today. 2002;5(1):30-35.

2. Song YS, Youn JR, Gutowski TG. Life cycle energy analysis of fiber-reinforced composites. Composites Part A: Applied Science and Manufacturing. 2009;40(8):1257-1265.

3. Hopewell J, Dvorak R, Kosior E. Plastics recycling: challenges and opportunities. Philosophical Transactions of the Royal Society B: Biological Sciences. 2009;364(1526):2115-2126.

4. Pickering SJ. Recycling technologies for thermoset composite materials - current status. Composites Part A: Applied Science and Manufacturing. 2006;37(8):1206-1215.
5. Witik RA, Teuscher R, Michaud V, Ludwig C, Månson JAE. Carbon fibre reinforced composite waste: An environmental assessment of recycling, energy recovery and landfilling. Composites Part A: Applied Science and Manufacturing. 2013;49:89-99.

6. Kouparitsas CE, Kartalis CN, Varelidis PC, Tsenoglou CJ, Papaspyrides CD. Recycling of the fibrous fraction of reinforced thermoset composites. Polymer Composites. 2002;23(4):682689 .

7. Buggy M, Farragher L, Madden W. Recycling of composite materials. Journal of Materials Processing Technology. 1995;55(3-4):448-456

8. Fu SY, Lauke B, Mäder E, Yue CY, Hu X. Tensile properties of short-glass-fiber- and short-carbon-fiber-reinforced polypropylene composites. Composites Part A: Applied Science and Manufacturing. 2000;31(10):1117-1125.

9. Pimenta S, Pinho ST. Recycling carbon fibre reinforced polymers for structural applications: Technology review and market outlook. Waste Management. 2011;31(2):378-392.

10. Luo Y, Zhao Y, Duan Y, Du S. Surface and wettability property analysis of CCF300 carbon fibers with different sizing or without sizing. Materials \& Design. 2011;32(2):941-946.

11. Nogueira CL, Paiva JMF, Rezende MC. Effect of the interfacial adhesion on the tensile and impact properties of carbon fiber reinforced polypropylene matrices. Materials Research. 2005;8(1):81-89.

12. Turner TA, Pickering SJ, Warrior NA. Development of recycled carbon fibre moulding compounds - Preparation of waste composites. Composites Part B: Engineering. 2011;42(3):517-525.

13. Brandup S, Immergut EM, McDowell W, eds. Polymer Handbook. New York: Wiley-Interscience; 1975.

14. Batista NL, Olivier P, Bernhart G, Rezende MC, Botelho EC Correlation between degree of crystallinity, morphology and mechanical properties of PPS/carbon fiber laminates. Materials Research. 2016;19(1):195-201.

15. González-Benito J. The nature of the structural gradient in epoxy curing at a glass fiber / epoxy matrix interface using FTIR imaging. Journal of Colloid and Interface Science. 2003;267(2):326-332.

16. Fraga F, Burgo S, Rodríguez Núñez E. Curing kinetic of the epoxy system BADGE $n=0 / 1,2$ DCH by Fourier Transform Infrared Spectroscopy (FTIR). Journal of Applied Polymer Science. 2001;82(13):3366-3372.

17. Yang J, Liu J, Liu W, Wang J, Tang T. Recycling of carbon fibre reinforced epoxy resin composites under various oxygen concentrations in nitrogen-oxygen atmosphere. Journal of Analytical and Applied Pyrolysis. 2015;112:253-261.

18. Rezende MC, Botelho EC, Costa ML. Compósitos Estruturais: Tecnologia e Prática. São Paulo: Artiliber; 2011.

19. Rezaei F, Yunus R, Ibrahim NA. Effect of fiber length on thermomechanical properties of short carbon fiber reinforced polypropylene composites. Materials \& Design. 2009;30(2):260-263. 